\title{
Penelitian dan Evaluasi Pendidikan
}

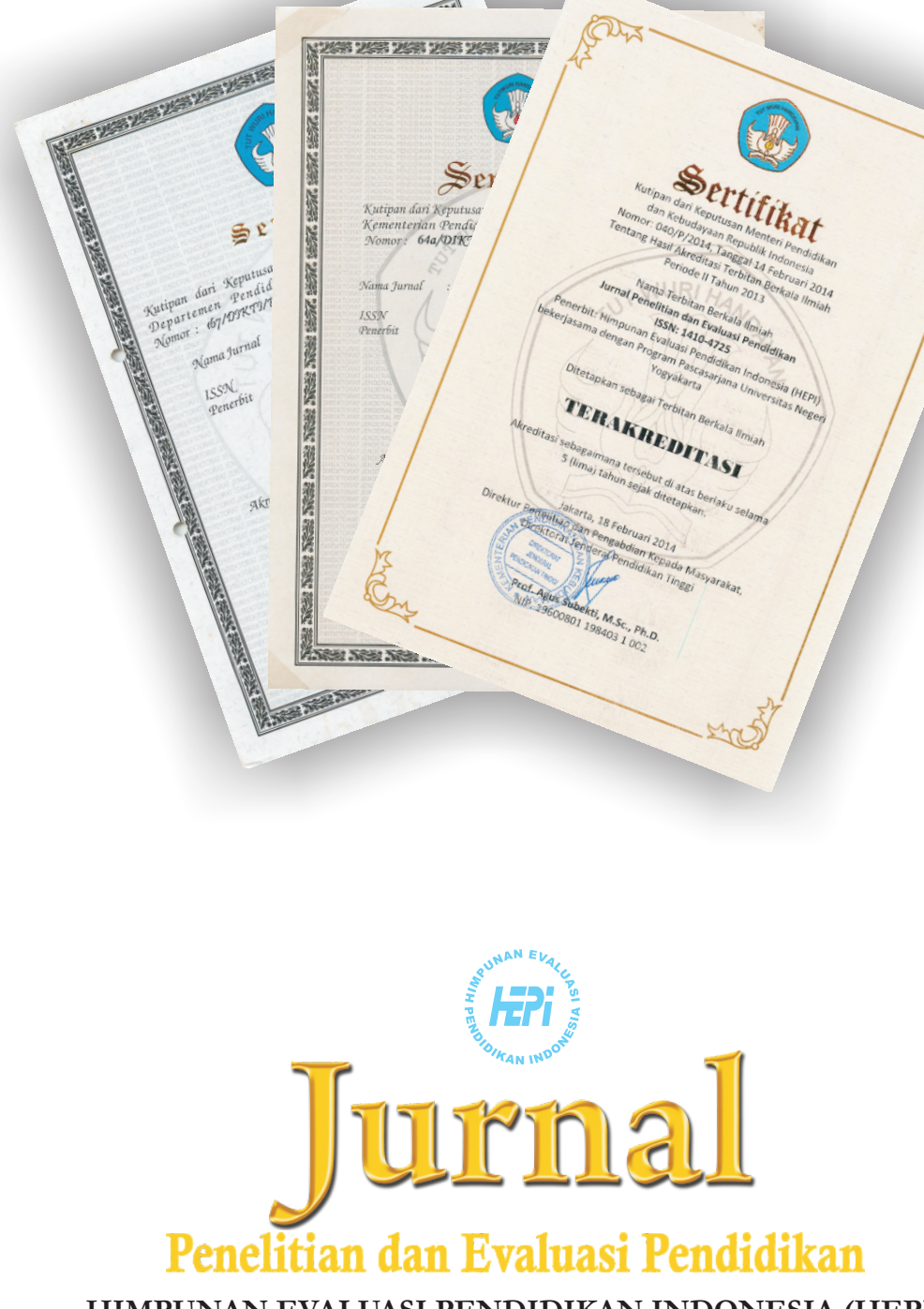

HIMPUNAN EVALUASI PENDIDIKAN INDONESIA (HEPI)

kerjasama dengan
PROGRAM PASCASARJANA UNIVERSITAS NEGERI YOGYAKARTA Alamat Redaksi : Kampus Karangmalang, Yogyakarta 55281. Telp. 0274550836 Fax : 0274520326

Website: http://journal.uny.ac.id/index.php/jpep e-mail: jurnalhepi@uny.ac.id, jurnalhepi@yahoo.com

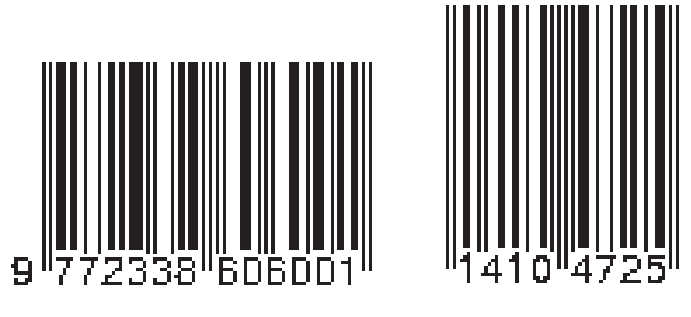

C. Heri Sulistiawan, Kualitas Soal Ujian Sekolah Matematika Program IPA dan Kontribusinya terhadap Hasil Ujian Nasional

Darodjat, Model Evaluasi Pembelajaran Akidah dan Akhlak

Darmivati Zucbdi di Madrasah Tsanawiyah (MTS

David, Badrun Kartowagiran, Evaluasi dan Strategi Pengembangan

Slamet PH SMA Indonesisch Nerderlandsche School (INS) Kayutanam

Fajriantbi, Wiwin Hendriani, Pengembangan Tes Berpikir Kritis dengan Pendekatan Berlian Gressy Septarini Item Response Theory

Kburiyah, Zamroni, Pengembangan Model Evaluasi Pengelolaan Pondok Pesantren Sumarno

Puji Yanti Fauriah, Pemetaan Mutu PAUD Fullday untuk Meningkatkan Kualitas Layanan Sugito dan Kelembagaan Program PAUD

Tissa Octavira Permatasari, Faktor Kognitif dan Non-kognitif pada Seleksi Mahasiswa Baru Yayi Suryo Prabandari, sebagai Prediktor terhadap Prestasi Akademik

Tri Nur Kristina

Vivi Meidianawaty, Eksplorasi Permasalahan dalam Implementasi Community-Based Education Widyandana, Tri Nur Kristina di Fakultas Kedokteran

Wasidi, Djemari Mardapi Pengembangan Instrumen Bakat Keguruan

Yuli Pribatni, Kumaidi, Pengembangan Instrumen Diagnostik Kognitif pada Mata Pelajaran Mundilarto IPA di SMP 


\section{KATA PENGANTAR}

Puji syukur kita panjatkan ke hadirat Tuhan Yang Maha Pemurah dan Pengasih karena atas rahmat-Nya Himpunan Evaluasi Pendidikan Indonesia (HEPI) bekerja sama dengan Program Pascasarjana (PPs) Universitas Negeri Yogyakarta dapat menerbitkan Jurnal Penelitian dan Evaluasi Pendidikan Volume 20, Nomor 1, Juni 2016. Jurnal Penelitian dan Evaluasi Pendidikan juga telah terakreditasi kembali oleh Kementerian Pendidikan dan Kebudayaan Direktorat Jenderal Pendidikan Tinggi Direktur Penelitian dan Pengabdian kepada Masyarakat. Berdasarkan kutipan dari keputusan Menteri Pendidikan dan Kebudayaan Nomor: 040/P/2014 tanggal 14 Februari 2014 tentang hasil akreditasi terbitan berkala ilmiah, Jurnal Penelitian dan Evaluasi Pendidikan ditetapkan sebagai terbitan berkala ilmiah terakreditasi. Akreditasi tersebut berlaku selama 5 (lima) tahun terhitung dari tanggal ditetapkannya atau sampai dengan tahun 2019.

Jurnal Penelitian dan Evaluasi Pendidikan memuat dan menyebarluaskan hasilhasil penelitian dan evaluasi pendidikan dosen, penelitian tesis mahasiswa S2, dan penelitian disertasi mahasiswa S3 dari berbagai perguruan tinggi di Indonesia. Hasil-hasil penelitian yang disampaikan pada jurnal ini tidak terbatas pada bidang evaluasi pendidikan tetapi juga hasil penelitian dan evaluasi pendidikan dalam arti luas, seperti bidang teknologi dan kejuruan, ilmu pengetahuan sosial, pendidikan luar sekolah, linguistik terapan, teknologi pembelajaran, manajemen pendidikan, pendidikan sains, dan pendidikan matematika.

Perbaikan sudah dilakukan untuk Volume 20, Nomor 1, Juni 2016 namun Dewan Redaksi tetap mengharap masukan dan kritik membangun dari civitas akademika agar terbitan berikutnya akan makin baik dan berkualitas. Adanya kekurangan-kekurangan pada jurnal ini kiranya dapat dimaklumi. Selanjutnya, atas perhatian pembaca dan bantuan mitra bebestari, editor, dan karyawan PPs Universitas Negeri Yogyakarta hingga dapat diterbitkannya jurnal ini diucapkan terima kasih.

Yogyakarta, Juni 2016

Ketua Redaksi 
Jurnal Penelitian dan Evaluasi Pendidikan 


\section{DAFTAR ISI}

C. Heri Sulistiawan Kualitas Soal Ujian Sekolah Matematika Program IPA dan

Kontribusinya terhadap Hasil Ujian Nasional

Darodjat,

Model Evaluasi Pembelajaran Akidah dan Akhlak di

Darmiyati Zuchdi

Madrasah Tsanawiyah (MTs)

David,

Evaluasi dan Strategi Pengembangan SMA Indonesisch

$27-44$

Badrun Kartowagiran,

Nerderlandsche School (INS) Kayutanam

Slamet PH

Fajrianthi,

Pengembangan Tes Berpikir Kritis dengan Pendekatan Item

$45-55$

Wiwin Hendriani,

Response Theory

Berlian Gressy Septarini

Khuriyah, Zamroni, $\quad$ Pengembangan Model Evaluasi Pengelolaan Pondok

Sumarno

Pesantren

Puji Yanti Fauriah,

Pemetaan Mutu PAUD Fullday untuk Meningkatkan

Sugito

Kualitas Layanan dan Kelembagaan Program PAUD

Tissa Octavira

Faktor Kognitif dan Non-kognitif pada Seleksi Mahasiswa

80-89

Permatasari,

Baru sebagai Prediktor terhadap Prestasi Akademik

Yayi Suryo Prabandari,

Tri Nur Kristina

Vivi Meidianawaty,

Eksplorasi Permasalahan dalam Implementasi Community-

$90-97$

Widyandana,

Based Education di Fakultas Kedokteran

Tri Nur Kristina

Wasidi,

Pengembangan Instrumen Bakat Keguruan

$98-110$

Djemari Mardapi

Yuli Prihatni, Kumaidi,

Pengembangan Instrumen Diagnostik Kognitif pada Mata

Mundilarto

Pelajaran IPA di SMP

$111-125$ 